\title{
MANUAL ESCOLAR: GUIA DE ESTUDO OU PRÁTICA DE COMPETÊNCIAS? ESTUDO COM PROFESSORES E ALUNOS DO ENSINO SECUNDÁRIO ${ }^{1}$
}

\author{
TEXTBOOKS: STUDY GUIDE OR PRACTICE SKILLS? STUDY WITH TEACHERS \\ AND STUDENTS OF SECONDARY EDUCATION
}

Maria Isabel Afonso ${ }^{2}$

\begin{abstract}
RESUMO: O trabalho apresentado corresponde a uma das fases $\mathrm{da}$ investigação para a tese de doutoramento cujo enfoque é o papel do manual de História no desenvolvimento de competências, na perspectivade professores e alunos do ensino secundário. Com este estudo procura-se compreender a utilização que professores e alunos fazem das actividades propostas nos manuais de História de $10^{\circ}$ ano, e como tais propostas se relacionam com o desenvolvimento das competências definidas no programa da disciplina. A amostra é constituída por 6 alunos a frequentar o $10^{\circ}$ ano, em escolas do Norte de Portugal, e 5 professores a lecionar esse ano de escolaridade. A análise dos dados recolhidos forneceu pistas para a evolução do estudo em processo e permitiu identificar percepções de professores e alunos sobre o uso do manual escolar e ainda concepções de alunos em História ao resolverem actividades que são propostas nesse recurso educativo.
\end{abstract}

Palavras-chave: Manual escolar. Percepções de professores. Manual de História. Concepções de alunos em História.

\begin{abstract}
The work presented here represents one of the stages of the research for the doctoral thesis which focus on the role of history textbooks in the development of skills, from the perspective of teachers and secondary school students. With this study seeks to understand how teachers and students use the activities proposed in $10^{\text {th }}$ grade history textbooks, and how such proposals relate to the development of the competences defined in the preliminary study. The sample consists of six students attending the $10^{\text {th }}$ grade in Northern Portugal schools and five teachers teaching this school level, subject program. The analysis of the collected data has provided clues to the evolution of the study in progress and allowed the identification of teachers and students perceptions on the use of textbooks and also the ideas of students about History by solving activities that are proposed in this educational resource.
\end{abstract}

Keywords: Textbooks. Teachers perceptions. History textbook. Conceptions of students about History.

\footnotetext{
${ }^{1}$ N. E. Manteve-se a grafia portuguesa.

2 Doutoranda em Educação, área de Metodologia do Ensino da História e Ciências Sociais, Universidade do Minho, Portugal. O estudo aqui apresentado faz parte da investigação em curso para a tese de doutoramento, orientada pela Professora Doutora Isabel Barca, e a apresentar na Universidade do Minho. Investigadora do CIEd, Universidade do Minho, projecto "Consciência histórica, consciênciasocial". Email: isa_afonso@sapo.pt
} 


\section{Introdução}

As concepções de manual escolar como instrumento de trabalho no processo de ensino/ aprendizagem têm vindo a sofrer mudanças fruto de alterações nas políticas educativas, nos programas e nas próprias concepções de ensino e das expectativas da sociedade em relação à função da escola.

A Lei de Bases do Sistema Educativo (Lei n.o 46/86, de 14 de Outubro) dedica especial atenção aos recursos educativos entendidos como "todos os meios materiais utilizados para conveniente realização da actividade educativa" (art. 041 , ponto 1), ocupando, o manual escolar, o primeiro lugar da lista de recursos educativos a privilegiar (art. 041 , ponto 2).

O Decreto-Lei n.o 369/90 (estabelecia o sistema de adopção e o período de vigência dos manuais escolares das diferentes disciplinas do ensino básico e secundário) definia o manual escolar como:

O instrumento de trabalho impresso, estruturado e dirigido ao aluno, que visa contribuir para o desenvolvimento de capacidades, para a mudança de atitudes e para a aquisição dos conhecimentos propostos nos programas em vigor, apresentando informação básica correspondente às rubricas programáticas, podendo conter elementos para 0 desenvolvimento de actividades de aplicação e avaliação efectuadas (PORTUGAL, Decreto-Lei no 369/90 de 26 de Novembro, artigo $2^{\circ}$ ).

O manual escolar é encarado como um instrumento privilegiado para o desenvolvimento de capacidades/atitudes; a aquisição de conhecimentos disciplinares; a aplicação e avaliação das aprendizagens dos alunos, mas não o considera um recurso exclusivo quando refere a possibilidade de os professores usarem outros recursos educativos e outras fontes de informação, desde que não represente custos adicionais para os alunos.

No sentido de assegurar a qualidade científica e pedagógica, o mesmo Decreto-Lei previa a existência de um sistema de apreciação e certificação dos manuais por comissões constituídas por especialistas das várias disciplinas a quem competiria a apreciação da qualidade dos manuais escolares. 
O Decreto-Lei n.0176/96 (estabelece o sistema de preço fixo do livro) reforça o papel do manual escolar como instrumento de trabalho do aluno:

\begin{abstract}
O instrumento de trabalho individual, constituído por um livro em um ou mais volumes, que contribua para a aquisição de conhecimentos e para o desenvolvimento de capacidades e das atitudes definidas pelos objectivos dos programas curriculares em vigor para cada disciplina, contendo informação básica necessária às exigências das rubricas programáticas (PORTUGAL, Decreto-Lei n.0176/96, artigo 10, alínea $\mathrm{g}$ ).
\end{abstract}

A Lei 47/2006 veio de novo definir o regime de avaliação, certificação e adopção dos manuais escolares do ensino básico e do ensino secundário, bem como os princípios e objectivos a que deve obedecer o apoio socioeducativo relativamente à aquisição e ao empréstimo de manuais escolares. Passam a existir duas fases para avaliação, certificação e adopção de manuais escolares. A primeira, a cargo de comissões de avaliação formadas por um mínimo de três e um máximo de cinco especialistas de reconhecida competência escolhidos de entre: docentes e investigadores do ensino superior; docentes do quadro de nomeação definitiva ; membros de sociedades ou associações científicas e pedagógicas de áreas relacionadas com a avaliação em causa. Estes membros não podem deter interesses directos ou indirectos com a publicação dos manuais. A segunda fase estará a cargo dos docentes que, nas escolas, adoptam um dos manuais certificados pelas comissões anteriormente referidas. Os critérios de avaliação e certificação manuais a considerar na sua apreciação são: o rigor científico, linguístico e conceptual; adequação ao desenvolvimento das competências; conformidade com os programas e orientações curriculares; qualidade pedagógica e didáctica; valores; possibilidade de reutilização e adequação ao período de vigência previsto; qualidade material, nomeadamente, a robustez e o peso.

O artigo 30, apresenta o manual escolar como:

O recurso didáctico - pedagógico relevante, ainda que não exclusivo, do processo de ensino e aprendizagem, concebido 
por ano ou ciclo, de apoio ao trabalho autónomo do aluno que visa contribuir para o desenvolvimento das competências e das aprendizagens definidas no currículo nacional para o ensino básico e secundário, apresentando informação correspondente aos conteúdos nucleares d os programas em vigor, bem como propostas de actividades didácticas e de avaliação das aprendizagens, podendo incluir orientações de trabalho para o professor (PORTUGAL, Lei n. ${ }^{0} 47 / 2006$ de 28 de Agosto, artigo 30, alínea a)

Esta Lei traz significativas alterações na concepção de manual escolar e na forma como se entende o percurso escolar do aluno. O manual é explicitamente considerado um recurso não exclusivo no processo de ensino/aprendizagem e o aluno é solicitado a pesquisar em outras fontes informação, diversificando assim, as perspectivas em relação ao saber e às fontes de informação disponíveis. O trabalho autónomo do aluno ganha relevância, o que deverá corresponder a propostas de actividades que proporcionem, mais do que a aplicação, a construção dos conhecimentos pelo aluno e a avaliação de competências definidas no currículo nacional. A não adopção de manuais é uma possibilidade desde que cada escola contemple, no seu projecto educativo, o recurso a outros materiais didáctico-pedagógicos.

O manual escolar parece, pois, apresentar-se mais como um guião de trabalho para alunos e professores, um referencial para o processo de ensino e aprendizagem não inviabilizando a utilização de "outros recursos didáctico - pedagógicos" entendidos como:

(...) recursos de apoio à acção do professor e à realização de aprendizagens dos alunos, independentemente da forma de que se revistam, do suporte em que são disponibilizados e dos fins para que foram concebidos, apresentados de forma inequivocamente autónoma em relação aos manuais escolares (PORTUGAL, Lei n. ${ }^{\circ}$ 47/2006 de 28 de Agosto, artigo 30, alínea c)

A assunção da importância do manual escolar (e materiais de apoio que o acompanham) no sistema de ensino português parece, pois, ser confirmada nos documentos que o Ministério da Educação tem produzido no sentido de regulamentar a sua elaboração e posterior avaliação e certificação, assim como o período de vigência, a política de preços e o regime de empréstimo de manuais. 
A relevância do manual escolar é também partilhada por muitos investigadores, na mediação entre programas e professores ou na parceria professor-texto, e ainda quanto a um papel decisivo na formação pedagógica e científica dos docentes (GERARD; ROEGIERS, 2003).

\section{O Estudo de Investigação}

Este estudo insere-se no âmbito do paradigma de investigação em educação histórica de natureza predominantemente qualitativa e procura responder às seguintes questões:

- Qual utilização fazem professores e alunos, no ensino secundário, do manual de História?

- Quais utilizações fazem das propostas de actividades apresentadas no manual de História?

- $\quad$ Qual relação existe entre as actividades propostas n o manual e o desenvolvimento de competências históricas nos alunos do ensino secundário?

A amostra é constituída por 6 alunos a frequentar a disciplina de História no $10^{\circ}$ ano em escolas do Norte de Portugal e por 5 professores a leccionar esse mesmo ano de escolaridade. Os critérios para a selecção foram a disponibilidade manifestada por professores e alunos; a acessibilidade das e os manuais adoptados. Os procedimentos foram os seguintes: Num primeiro momento, e após ter sido leccionado o ponto "A Educação para o exercício público do poder" [na Grécia Antiga] propôs-se aos alunos participantes que resolvessem as questões, propostas no manual escolar adoptado para esse ponto do programa. A tarefa devia ser resolvida em sala de aula, por escrito e individualmente, e com o manual aberto para consulta. Recomendou-se aos alunos que procurassem dar respostas fundamentadas nas fontes, mas que não se limitassem a usar e/ou copiar a informação explícita da fonte. Num segundo momento, passou-se à entrevista áudio-gravada, de alunos e professores, realizada pela investigadora, que se deslocou aos locais do país em que se encontravam os participantes. A entrevista seguia um guião de orientação e continha 
questões sobre a utilização do manual, em geral, e das actividades aí propostas e questões sobre a utilização de um tópico concreto: "A Educação para o exercício público do poder".

\section{Análise de Dados}

A análise dos dados recolhidos forneceram pistas para a evolução do estudo em processo e permitiram identificar percepções sobre o uso que professores e alunos fazem do manual de História do ensino secundário e concepções de alunos sobre as actividades que são propostas nesse recurso educativo. Permitiram, também, identificar as seguintes dimensões e categorias de análise:

Dimensão de análise: O manual escolar como recurso didácticopedagógico dentro e fora da sala de aula.

Dimensão de análise: Concepções de alunos sobre as actividades apresentadas no manual escolar.

Na dimensão de análise: O manual escolar como recurso didácticopedagógico, dentro e fora da sala de aula, criaram-se as seguintes categorias:

- $\quad$ Utilização do manual de História (dentro e fora da sala de aula) pelos alunos e professores (Quadro 1)

- $\quad$ Utilização das actividades propostas no manual de História (dentro e fora da sala de aula) pelos alunos e professores (Quadro 2).

O quadro 1, apresenta a sistematização dos dados relativos à utilização que professores e alunos fazem do manual escolar. 
Quadro 1 - Utilização do manual de História pelos alunos e professores

\begin{tabular}{|c|c|c|c|c|}
\hline \multicolumn{2}{|c|}{ Construto } & Frequência & No & No de \\
\hline \multirow[t]{6}{*}{ Utilização } & \multirow[t]{3}{*}{$\begin{array}{c}\text { Dentro da sala de } \\
\text { aula }\end{array}$} & $\begin{array}{c}\text { Sempre/quase } \\
\text { sempre }\end{array}$ & 4 & 3 \\
\hline & & Às vezes/ depende & 1 & 3 \\
\hline & & Raramente/Nunca & 0 & \\
\hline & \multirow[t]{3}{*}{ Fora da sala de aula } & $\begin{array}{c}\text { Sempre/quase } \\
\text { sempre }\end{array}$ & 5 & \\
\hline & & Ás vezes/depende & 0 & 5 \\
\hline & & Raramente/ Nunca & 0 & 1 \\
\hline
\end{tabular}

Como o quadro mostra, o manual escolar é frequentemente utilizado, dentro da sala de aula, tanto por professores como pelos alunos que fizeram parte da amostra. Apenas um professor diz que o uso do manual em sala de aula depende das fontes e do texto informativo apresentados para os conteúdos a leccionar. Fora da sala de aula, todos os professores afirmam utilizar o manual frequentemente para orientar/ preparar a aula e tomar conhecer das propostas aí apresentadas.

Quanto ao uso do manual escolar pelos alunos em sala de aula, 3 dizem usá-lo frequentemente e 3 usam quando o professor o solicita e, essencialmente, para a leitura e análise das fontes. Afirmam preferir "ouvir a explicação do professor". Fora da sala de aula, a maioria dos alunos (5) usam o manual às vezes e 1 aluna raramente usa. O manual é usado fora da sala para estudar, nomeadamente para os testes e para resolver as actividades quando os professores solicitam. Três alunos dizem achar aquele "manual difícil" e preferem "estudar pelos apontamentos da professora". 
Quadro 2 - Utilização das actividades propostas no manual de História pelos alunos e professores e (dentro e fora da sala de aula)

\begin{tabular}{|c|c|c|c|c|c|}
\hline \multicolumn{2}{|c|}{ Construto } & Elementos & Frequência & N.O & N.o de \\
\hline \multirow{6}{*}{ Utilização } & \multirow{3}{*}{$\begin{array}{l}\text { Dentro da } \\
\text { sala de } \\
\text { aula }\end{array}$} & \multirow{3}{*}{ Actividades } & $\begin{array}{c}\text { Sempre/quase } \\
\text { sempre }\end{array}$ & 3 & 3 \\
\hline & & & $\begin{array}{c}\text { Às } \\
\text { vezes/Algumas } \\
\text { das actividades }\end{array}$ & 2 & 3 \\
\hline & & & $\begin{array}{c}\text { Raramente/Nun } \\
\text { ca }\end{array}$ & 0 & \\
\hline & \multirow{3}{*}{$\begin{array}{c}\text { Fora da } \\
\text { sala de } \\
\text { aula }\end{array}$} & \multirow{3}{*}{ Actividades } & $\begin{array}{c}\text { Sempre/quase } \\
\text { sempre }\end{array}$ & 0 & \\
\hline & & & \begin{tabular}{|c|} 
Às \\
vezes/Algumas \\
das actividades
\end{tabular} & 0 & 4 \\
\hline & & & $\begin{array}{c}\text { Raramente/Nun } \\
\text { ca }\end{array}$ & 0 & 2 \\
\hline
\end{tabular}

O quadro 2 mostra que as actividades/questões propostas nos manuais adoptados são usadas em sala de aula. A maioria dos professores (3) diz usar frequentemente e 2 dizem usar às vezes e algumas das actividades propostas. Quanto aos alunos, 3 dizem que resolvem frequentemente as actividades/questões em sala de aula e os restantes (3) resolvem algumas das actividades/questões propostas no manual adoptado. Fora da sala de aula, 4 alunos dizem que resolvem, às vezes, as actividades e/ou algumas das actividades e 2 raramente ou nunca resolvem essas actividades. Os alunos que resolvem as actividades questões em casa usam-nas para consolidar conhecimentos para os testes de avaliação e/ou quando os professores solicitam como trabalho de casa. Dois alunos raramente ou nunca resolvem as actividades porque acham o "manual difícil" (1) ou porque é "uma questão de preguiça". 


\section{Concepções de Alunos Sobre as Actividades Propostas no Manual Escolar}

As respostas dos alunos às actividades/questões propostas para o ponto do programa "A Educação para o exercício público do poder" foram analisadas $e$ identificaram-se as seguintes categorias e subcategorias no uso das fontes:

1-Incoerência de interpretação

2-Cópia válida de elementos de fontes
a)"chapa"
b) contextualizada
c) com juízo pessoal.

\section{Exemplos de respostas nas diferentes categorias}

1 - Incoerência de interpretação

A2 - Com isto quer dizer que quanto mais gente exercer cargos políticos as opiniões vão sendo diferentes e nem sempre melhores para o povo.

2. Cópia válida de elementos das fontes:

a) "chapa"

A1- Aristóteles afirma isso (...) uma vez que a democracia parece alicerçarse em duas bases: o poder supremo da maioria e a liberdade.

b) essencial

A1 - O objectivo de educar em conformidade com o regime é atingir a capacidade de governo.

A3 - Aristóteles afirma que acaba por "acontecer o contrário do que é mais adequado ao interesse comum, pois em vez de se defender a vontade da maioria, ganha a vontade de alguns. Isto deve-se à má compreensão da liberdade.A4- Afirma-se que a educação dos gregos foi mais oral do que escrita porque além de existirem poucas obras escritas, os gregos preferiam e tinham maior facilidade em falar do que escrever. A educação 
era muito mais fácil por meio da conversação.

A2- $O$ objectivo de Aristóteles é que os cidadãos pudessem adquirir hábitos de cidadania conforme o regime, tendo capacidade de governar.

c) contextualizada

A5- As condições das mulheres na Grécia Antiga variavam de cidade para cidade. Por exemplo, em Atenas depois dos 7 anos, as raparigas iam à escola enquanto que as raparigas permaneciam em casa no gineceu. Quando tinham cerca de 15 anos, as raparigas casavam com homens de uma geração anterior e da mesma família. A moça ficava a pertencer ao marido e tinha de cuidar dos seus filhos. Cuidava deles no gineceu onde Ihes ensinava a falar e outros ensinamentos básicos.

A6- A educação dos gregos foi mais feita oralmente, pois estes eram um povo que preferia falar e ouvir do que propriamente ler e escrever. Os gregos demonstraram essas preferências em vários campos. Nomeadamente a arquitectura, na literatura, na filosofia. Por exemplo, havia uma pessoa que lia uma tragédia ou uma comédia e havia muitas que a conheciam através da representação teatral. Os filósofos utilizaram o discurso e a discussão para dar o seu ponto de vista e opinião.

d) com juízo pessoal

A6- A mulher na Grécia Antiga não frequentava a escola (isso era reservado aos rapazes), ficavam em casa, no gineceu com a mãe e as servas onde completavam a sua formação até ao casamento (a idade adulta). No casamento, a mulher passava a ser "propriedade" do marido e casava-se muito cedo (por volta dos 15 anos) enquanto os noivos eram de uma geração anterior e da mesma família.

A1- Segundo Aristóteles, a liberdade e igualdade de cada um fazer aquilo muito Ihe apraz. Por um lado concordo por outro não, pois para alguns a liberdade é fazer aquilo que Ihes apetece mas deveria haver limites.

A3 - Aristóteles defende que a liberdade deveria ser exercida com respeito aos que nos rodeiam e não fazendo o que lhes apetece. A igualdade deve ser praticada pois obedecer à vontade de alguns não é agir com igualdade. Concordo com a opinião de Aristóteles, visto que para se viver em comunidade é preciso respeitar tanto a igualdade como a 
liberdade.

A categorização das ideias que emergiram da análise das respostas dos alunos ás actividades/questões propostas nos manuais foram agrupadas em 2 conjuntos de 3 alunos cada, segundo o manual adoptado e as percepções dos alunos sobre as actividades aí propostas. Assim, o primeiro grupo de alunos (A1 a A3) manifestou preferência pelas actividades/questões de "Síntese" de informação com base em fontes, em detrimento das questões de "Análise" de fontes propostas no manual escolar adoptado (MEPE). O segundo grupo de alunos (A4 a A6), apesar de dizerem resolver frequentemente as questões colocadas ás fontes (Quadro 2), afirmam "preferir os apontamentos da professora" porque acham o manual e algumas fontes "difíceis" de entender (MEA).

Quadro 3- Distribuição das respostas por categorias e grupo de alunos / manual

\begin{tabular}{|c|c|c|}
\hline Categorias & A1- A3 & A4-A6/MEA \\
\hline 1-Incoerência de interpretação & 0 & 1 \\
& & \\
\hline 2- Cópia válida de elementos de fontes & & \\
\hline a)"chapa" & & 2 \\
\hline c) contextualizada & 0 & 9 \\
\hline d) com juízo pessoal & 5 & 3 \\
\hline TOTAL & 6 & 3 \\
\hline
\end{tabular}

De acordo com os dados apresentados no Quadro 3, as respostas dos alunos distribuem-se por 2 níveis de progressão oscilando entre a incoerência de interpretação e a cópia válida de elementos de fonte com juízo pessoal. No primeiro grupo de alunos (A1-A3), as respostas dos alunos situam-se na categoria 2- Cópia válida de elementos de fontes e distribuem-se pelas subcategorias b) essencial, c) contextualizada e d) com juízo pessoal. No segundo grupo (A4- $A 6$ ), as respostas dos alunos distribuem-se por todas as categorias, concentrando-se o maior número 
(9) na categoria 2 - Cópia válida de elementos de fontes, na subcategoria b) essencial. Em síntese, o primeiro grupo de alunos apresenta um raciocínio histórico mais elaborado do que o segundo, indiciando alguma consistência com as percepções sobre o uso do manual e as propostas de actividades/questões. Na globalidade, as respostas dos alunos revelam uma maior preocupação em buscar informação nas fontes do que a reflexão e um raciocínio próprio (BORRIES, B.; KÖRBER, A.; MEYER HAMMER, J.( 2002).

\section{Considerações Finais}

A importância que o manual reveste no quotidiano escolar de professores e alunos, parece ser inegável, sendo um dispositivo pedagógico que, na prática, poderá assumir um carácter prescritivo. Embora possa usar outros materiais e fontes de informação, o professor tende a privilegiar o uso do manual escolar na sala de aula no processo de ensino e aprendizagem, quer a nível da planificação das aulas, quer a nível da sua implementação.

No actual sistema de ensino português, o ensino e a consequente avaliação, tanto no ensino básico como no ensino secundário, devem proporcionar o desenvolvimento de diversas competências nos alunos, para lá da simples reprodução da informação (PORTUGAL, Ministério de Educacão, DES, 2001). Logo, o manual e os materiais que o acompanham terão de cumprir esta função, a de desenvolver competências diversas e a de avaliar o desenvolvimento das mesmas. Embora o manual seja geralmente elaborado de forma a adaptar-se a um aluno "médio", em abstracto, ele tem um uso muito variado. Sabe-se hoje que aquilo que veicula é entendido de diferentes formas pelos seus destinatários. As concepções prévias influenciam essa diversidade de leituras.

Actualmente são bastantes e variados os manuais que proliferam no mercado e o leque diversificado da oferta podem proporcionar escolhas de melhor qualidade. Tendo em conta o evoluir do conhecimento, e uma vez que se torna impossível de dominar, o manual também assume uma 
importante função relacionada com a informação científica. Em termos pedagógicos, pode também contribuir para a actualização do docente, através da apresentação de novas propostas de metodologia de ensino e de aprendizagem, assumindo, assim, uma função importante na formação contínua. Assim, esta dimensão de instrumento na formação contínua dos professores não deve ser esquecida no momento da sua concepção.

Conhecer as formas como alunos e professores fazem a leitura do manual e das actividades aí propostas seria de particular importância, na medida em que pode fornecer pistas interessantes que auxiliem a sua concepção, adopção e uso, com vista ao seu papel no desenvolvimento de competências dos jovens, trabalho que começa a emergir em Portugal (MOREIRA, 2005; COSTA, 2007; SILVA, 2007).

O trabalho com fontes históricas com suportes diversos e mensagens diversas é um dos fundamentos da Educação Histórica e um desafio para os professores (BARCA, 2005). Tornar os alunos capazes de interrogar as fontes, de compreendê-las pelo que são e pelo que elas podem dizer acerca do passado (evidência) poderá não ser um trabalho fácil considerando que os alunos tendem a usar as fontes como informação que Ihes dá acesso directo ao passado. (ASHBY, 2003),

Parece também pertinente perceber que papel esse instrumento desempenha no percurso de aprendizagem dos alunos, que conhecimentos os alunos constroem a partir das actividades aí propostas e as competências que essas actividades privilegiam/não privilegiam.

\section{Referências}

ASHBY, R. Conceito de evidência histórica: exigências curriculares e concepções dos alunos. In BARCA, I. (Org.). Educação histórica e museus. Actas das Segundas Jornadas Internacionais de Educação Histórica. Braga: Centro de Investigação em Educação, Universidade do Minho, 2003, p.3747.

BARCA, I. Educação histórica: uma nova área de investigação. In ARIAS NETO, J. M. (Org.). Dez anos de pesquisa em ensino de história. Londrina: AtritoArt, 2005. p. 15-25. 
BORRIES, B., KORBER, A., MEYER- HAMM J. Uso reflexivo de los manuales escolares de historia: resultados de una encuesta realizada a docentes, alumnos y universitarios. Enseñaza de las Ciencias Sociales. Revista de investigación, n. 5 , Marzo,. 2006.

COSTA, M. A. Ideias de professores sobre a utilização de fontes dos manuais de História. Um estudo no 3.0 Ciclo do Ensino Básico Dissertação. de mestrado não publicada. Braga: Universidade do Minho, 2007.

GERARD, F.; ROEGIERS, X. Des manuels pour apprendre. Concevoir, évaluer, utiliser. Bruxelles: De Boeck. 2003.

MOREIRA, O. Concepções dos alunos acerca da Televisão e conheci mento histórico. Dissertação de mestrado não publicada. Braga: Universidade do Minho, 2002

PORTUGAL. Ministério DA Educação. Programa de História A, 10.0, 11.0 e 12. ${ }^{\circ}$ ano. Curso Científico Humanístico de Ciências Sociais e Humanas. Lisboa: ME - DES, 2002.

SILVA, R. A construção do conhecimento histórico a partir das actividades propostas pelos manuais: Um estudo com alunos do $2 .^{\circ}$ ciclo do Ensino Básico. Dissertação de Mestrado não publicada. Braga: Universidade do Minho, 2007. 